\title{
Optimization of Supply Trains in Tunnel Boring Operation Using Tunnel Boring Machines
}

\author{
[ Jirawat Damrianant ]
}

\begin{abstract}
A large drainage-tunnel with an inside diameter of $5 \mathrm{~m}$ will be constructed in Bangkok using tunnel boring machines (TBM) by the end of 2018 . One of the most challenging problems in this operation is how to determine the number of supply trains containing muck cars for the muck evacuation process during the boring. This paper presents an optimization of the number of the supply trains employed in the project so that the operation of the train fleet will be well synchronized with that of the TBM. Petri Net-based models and their simulation are used as the means for the optimization. The COSMOS simulator, which is reliable software for running Pet Net-based models, is used for the simulation. The simulation results indicate that the optimal numbers of supply trains are 2, 3, 4 and 5 for the tunnel lengths of 0-0.9, 0.9-2.7, 2.7-4.5 and 4.5-5.5 km, respectively. The analysis of these results also offers the numbers and the locations of the double track positions for each interval of the tunnel lengths. For example, when the length of the tunnel under construction is $4.5-5.5 \mathrm{~km}$, there should be 3 double track points located at $1.8,3.6$ and $4.5 \mathrm{~km}$ from the starting shaft for the operation to be optimal.
\end{abstract}

Keywords-optimization, simulation, model, operation, tunnel, boring, supply train, TBM

\section{Introduction}

The Beung-Nongbon drainage-tunnel project is scheduled to be constructed in Bangkok, Thailand, in 2018. The tunnel is a primary part of the drainage system intending to lessen flooding problem in the east of Bangkok. It was designed to drain water from Nongbon retention pond to the Chao Phraya River. The tunnel is $9.4 \mathrm{~km}$ long with an inside diameter of $5 \mathrm{~m}$. Two tunnel boring machines (TBM) will be used for this project. The construction cost of the entire project is approximately 155 million USD. One of the most challenging problems in this operation is how to determine the number of supply trains containing muck cars for the muck evacuation process during the boring by the TBM. The problem arises from the fact that a portion of the tunnel has an unusually long length, i.e. $5.5 \mathrm{~km}$, without a vertical shaft for muck disposal. In other projects, a shaft is usually located at the maximum distance of $1 \mathrm{~km}$ apart from the adjacent shaft along the tunnel under construction. Because of the exceptional long length without a vertical shaft, no historical data on the estimation of the optimal number of supply trains is available. The supply trains are used in the operation for the evacuation of the muck that results from the excavation of the TBM. The supply train are also used to transport the segments for the tunnel lining from the tunnel shaft to the TBM. Therefore, the operation of the supply trains must be synchronized with that of the TBM.

Jirawat Damrianant

Thammasat University

Thailand
The purpose of this paper is to present an approach for the optimization of the number of the supply trains employed in the project so that the operation of the train fleet will be well synchronized with that of the TBM.

\section{Research Methodology}

The optimization in this research is performed through the modeling and simulation approach. Petri Net-based models for the tunnel boring operation are created. The models are then simulated using the COSMOS simulator which is reliable software for running Pet Net-based or COSMOS models. The simulator was developed by the author's research team based on the COSMOS system (Construction Oriented Simulation MOdeling System) [1] which is an extension of the Pet Nets methodology [2]-[4]. The analysis of the results of the simulation yields the optimal number of supply trains to be engaged in the operation. It also gives the numbers and the locations of the double track positions for each interval of the tunnel lengths.

\section{Excavation Process and Related Data}

Each TBM used in the boring operation is divided into 2 main parts, i.e. a shield body and a back-up system. The shield body is in direct contact with the soil and the cutting face. There is a cutter head on the front of the shield body. The other main part is the back-up system which is the rolling portion that follows the shield. It carries all the accessories to allow the continuing advance of the TBM. To follow the shield body, the back-up system needs to move on a railroad track having particular rails of its own, which are separated from the rails for the supply trains. [5]

A supply train used in this project comprises 1 locomotive, 2 segment cars, tentatively 6 muck cars and a flat car.

Three activities related to the supply trains are performed within the back-up system as follows:

1. Evacuation of soil: The muck, which is the excavated material that results from the excavation of the cutter head of the TBM, is transferred from a crew conveyor to a belt conveyor. The muck is then dumped into muck cars, which are a part of a supply train. The train subsequently transports the muck to the nearest tunnel shaft where a vertical transportation system lifts the muck to the surface level for disposal.

2. Conveyance of segments and other supplies: The segments for the tunnel lining and other supplies, which allow the advance of the TBM, are transported to the back-up system using the supply trains. 
3. Relocation of rails: Two rails, $6 \mathrm{~m}$ each, at the back of the back-up system must be relocated at a certain point in time to allow the advance of the back-up system.

The lining of the tunnel is composed of pre-cast concrete segments. The installation of the segments is performed by equipment called the erector arm, which is located at the rear body of the shield. Once the TBM has completed the excavation for 1 ring, the erector commences the installation of the segments. The erector takes each of the segments from the segment feeder and places each one in its right position. The last segment, which is called key, closes the ring and allows the TBM to commence another boring cycle. The TBM installs one ring after another, which allows the tunnel length to increase until the construction of the tunnel is finished. [5] In this project, a ring of the tunnel lining is composed of 6 segments. The excavation for 1 ring causes $40 \mathrm{~m}^{3}$ (loose volume) of muck. One kilometer of the tunnel lining consists of 900 rings, approximately.

When a supply train arrives at the TBM, it stops at the front part of the back-up system at the back of the shield body. The train is then split into 2 parts. The first part comprises the 2 segment cars and the flat car. The other part is a group of the muck cars.

After the group of muck cars has been separated from the other part of the supply train, it moves backward to the end of the belt conveyor in readiness to receive the excavated muck. Once the group of muck cars is at this position, TBM can begin excavating a new cycle, which results in the $40 \mathrm{~m}^{3}$ of the muck. After the completion of 1 cycle of the excavation, a crane, called the primary host, which is standing by at the back-up system, picks a segment up one by one from the segment cars and carries them to the segment feeder. The segment feeder forwards the segments sequentially to the erector for an installation of 1 ring as described above. [5]

For every 4 rounds of the supply trains coming in the back-up system, other materials apart from the segments are carried by the trains on the flat car. The materials comprise $6 \mathrm{~m}$ long rails for the extension of the rails for the supply train itself, pipes and other accessories. When the train arrives at the back-up system and is at the desired position, those materials are transferred to the back-up system using the primary hoist.

Once the muck cars have been loaded and the segment including the flat cars have been unloaded, all of the cars are then assembled to form a complete supply train again. The train then departs from the back-up system to the shaft allowing the next one to come in. When the train has been assembled and is ready to leave the back-up system, the operation of the supply train at the TBM is considered complete for 1 cycle given that the relocation of the rails for the back-up system is not needed. In the case when the relocation is required, the train will not immediately depart the back-up system after it has been assembled. The train will instead be involved in the relocation activity until the activity is done. After that, the train will be ready to leave the back-up system. At this point, it can be said that the operation of the supply train at the TBM is finished.

For the TBM, a cycle of its operation comprises 2 main activities, i.e. the soil excavation and the installation of the segments for 1 ring. The cycle commences from the excavation and finishes when 1 ring of the tunnel lining is installed.

Two rails, $6 \mathrm{~m}$ each, at the back of the back-up system must be relocated for every 10 rings installed. The rails will be removed from their current positions and reinstalled at the head of the track, which is near the rear of the shield body. This will allow the continuing advance of the back-up system.

\section{Iv. Muck Evacuation Model}

A model for the muck evacuation, the tunnel boring and the segment installation is developed using a COSMOS system.

The model presented in this paper is for the case where the management of the movement of the supply trains is of a typical style when a single railway track is used. The typical style is that the outgoing train (the train moving from the TBM to the shaft) can pass the double track point if and only if there is an incoming train parking at the point. Otherwise, the outgoing train must wait at that point until there is an incoming train. Once the incoming train has passed that point, the outgoing train can move forward to the next double track point or to its destination.

The main model is adjusted into several models to represent the cases where the tunnel lengths are extended from the advance of the TBM. The tunnel lengths in the models mean the lengths from the shaft to the furthest position at the front part of the back-up system where the supply trains are. Table I provides the cases for the modeling. These cases differ by the tunnel lengths, the number of the double tracks along the lengths and the number of the supply trains. Fig. 1 illustrates the track layout of case 4 from Table I.

\section{TABLE I. CASES FOR Muck Evacuation Model}

\begin{tabular}{|c|c|c|c|}
\hline Cases & $\begin{array}{c}\text { Tunnel Lengths } \\
\text { (km) }\end{array}$ & $\begin{array}{c}\text { Number of Double } \\
\text { Track Points }\end{array}$ & $\begin{array}{c}\text { Number of } \\
\text { Supply Trains }\end{array}$ \\
\hline 1 & 5.5 & 3 & 4 \\
\hline 2 & 5.5 & 3 & 3 \\
\hline 3 & 5.5 & 3 & 2 \\
\hline 4 & 5.5 & 2 & 4 \\
\hline 5 & 5.5 & 2 & 3 \\
\hline 6 & 5.5 & 2 & 2 \\
\hline 7 & 4.5 & 3 & 4 \\
\hline 8 & 4.5 & 3 & 3 \\
\hline 9 & 4.5 & 3 & 2 \\
\hline 10 & 4.5 & 2 & 4 \\
\hline 11 & 4.5 & 2 & 3 \\
\hline 12 & 4.5 & 2 & 2 \\
\hline 13 & 3.5 & 2 & 4 \\
\hline 14 & 3.5 & 2 & 3 \\
\hline 15 & 3.5 & 2 & 2 \\
\hline 16 & 2.5 & 2 & 4 \\
\hline 17 & 2.5 & 2 & 3 \\
\hline 18 & 2.5 & 2 & 2 \\
\hline 19 & 2.5 & 1 & 3 \\
\hline
\end{tabular}


Proc. of the Sixth Intl. Conf. Advances in Civil, Structural and Mechanical Engineering - CSM 2018

Copyright (C) Institute of Research Engineers and Doctors, USA. All rights reserved.

ISBN: 978-1-63248-150-4 doi: 10.15224/978-1-63248-150-4-23

Case-4:

Distance $=5.5 \mathrm{~km}$, Double Track $=2$ points,

Supply Train $=4$ trains

$O=1$ Supply Train

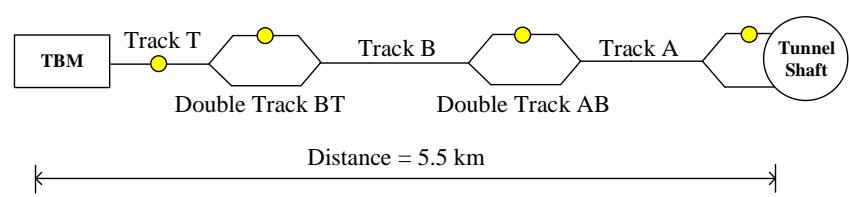

Figure 1. Track layout of case 4 from Table I.

A COSMOS model of the operation for case 4 from Table I is presented in Fig. 2.

The durations of the activities of the tunnel boring operation, which include excavation, muck evacuation and segment installation, are given in Table II. These durations were obtained from the historical records for the tunnel boring operations of the same kind documented by an engineering team of the TERRATEC Ltd. which is the world-renowned Australian designer and manufacturer of tunnel boring machines.

TABLE II. AVERAGE ACTIVITY DURATIONS FOR THE OPERATION

\begin{tabular}{|c|c|c|}
\hline $\begin{array}{c}\text { Short } \\
\text { Names }\end{array}$ & Activities & $\begin{array}{c}\text { Activity } \\
\text { Durations } \\
\text { (minute) }\end{array}$ \\
\hline T1 & $\begin{array}{l}\text { Locomotive Goes to TBM on Track } \mathrm{A}^{\mathrm{a}} \\
(2.3 \mathrm{~km})\end{array}$ & 25 \\
\hline $\mathrm{T} 2$ & $\begin{array}{l}\text { Locomotive Goes to TBM on Track B }{ }^{\mathrm{a}} \\
(2.3 \mathrm{~km})\end{array}$ & 25 \\
\hline T3 & $\begin{array}{l}\text { Locomotive Goes to TBM on Track } \mathrm{T}^{\mathrm{a}} \\
(0.9 \mathrm{~km})\end{array}$ & 11 \\
\hline T4 & $\begin{array}{l}\text { Split Muck Cars from Segment and Flat } \\
\text { Cars and Muck Cars Move to Belt } \\
\text { Conveyor End }\end{array}$ & 1 \\
\hline T5 & Excavate Soil for 1 Ring & 25 \\
\hline T6 & Install 1 Ring (6 Segments) & 25 \\
\hline $\mathrm{T} 7$ & Unload Segment Cars & 5 \\
\hline $\mathrm{T} 8$ & Unload Flat Car & 5 \\
\hline T9 & Assembling Muck and Segment+Flat Cars & 1 \\
\hline T10 & $\begin{array}{l}\text { Loco Moves to Re-railing Spot and Is } \\
\text { Involved in the Re-railing Activity for } \\
\text { Every } 10 \text { Ring Installed }\end{array}$ & 12 \\
\hline T11 & Unload Flat Car for Re-railing & 5 \\
\hline T12 & $\begin{array}{l}\text { Locomotive Returns to Shaft on Track } \mathrm{T}^{\mathrm{a}} \\
(0.9 \mathrm{~km})\end{array}$ & 11 \\
\hline T13 & $\begin{array}{l}\text { Locomotive Returns to Shaft on Track B }{ }^{\mathrm{a}} \\
(2.3 \mathrm{~km})\end{array}$ & 25 \\
\hline T14 & $\begin{array}{l}\text { Locomotive Returns to Shaft on Track } \mathrm{A}^{\mathrm{a}} \\
(2.3 \mathrm{~km})\end{array}$ & 25 \\
\hline T15 & Unload Locomotive at Shaft & 50 \\
\hline
\end{tabular}

\section{v. Simulation Results and Result Analysis}

The simulation results from the COSMOS simulator for the cases shown in Table I are summarized in Table III.

TABLE III. SOME SimUlation RESUlts

\begin{tabular}{|c|c|c|}
\hline Cases & $\begin{array}{c}\text { Average Number } \\
\text { of Rings Installed } \\
\text { in 24 } \mathbf{~ h r}^{\mathbf{a}}\end{array}$ & \multicolumn{1}{c|}{ Remark } \\
\hline 1 & Deadlock & Operation stops at $\mathrm{t}=151$ minutes \\
\hline 2 & Deadlock & Operation stops at $\mathrm{t}=101$ minutes \\
\hline
\end{tabular}

\begin{tabular}{|c|c|c|}
\hline Cases & $\begin{array}{l}\text { Average Number } \\
\text { of Rings Installed } \\
\text { in } 24 \mathbf{h r}^{\mathrm{a}}\end{array}$ & Remark \\
\hline 3 & Deadlock & Operation stops at $\mathrm{t}=51$ minutes \\
\hline 4 & 27.8 & \\
\hline 5 & Deadlock & Operation stops at $\mathrm{t}=101$ minutes \\
\hline 6 & Deadlock & Operation stops at $\mathrm{t}=51$ minutes \\
\hline 7 & Deadlock & Operation stops at $\mathrm{t}=151$ minutes \\
\hline 8 & Deadlock & Operation stops at $\mathrm{t}=101$ minutes \\
\hline 9 & Deadlock & Operation stops at $\mathrm{t}=51$ minutes \\
\hline 10 & 27.8 & \\
\hline 11 & Deadlock & Operation stops at $\mathrm{t}=101$ minutes \\
\hline 12 & Deadlock & Operation stops at $\mathrm{t}=51$ minutes \\
\hline 13 & 27.8 & \\
\hline 14 & Deadlock & Operation stops at $\mathrm{t}=101$ minutes \\
\hline 15 & Deadlock & Operation stops at $\mathrm{t}=51$ minutes \\
\hline 16 & 27.8 & \\
\hline 17 & Deadlock & Operation stops at $\mathrm{t}=101$ minutes \\
\hline 18 & Deadlock & Operation stops at $\mathrm{t}=51$ minutes \\
\hline 19 & 27.8 & \\
\hline 20 & 27.8 & $\begin{array}{l}\text { Maximum permissible length of } \\
\text { track T }\end{array}$ \\
\hline 21 & 27.3 & $\begin{array}{l}\text { Distance exceeds max permissible } \\
\text { length of track } T\end{array}$ \\
\hline 22 & 26.3 & $\begin{array}{l}\text { Distance exceeds max permissible } \\
\text { length of track T }\end{array}$ \\
\hline
\end{tabular}

no outgoing train is therefore allowed to pass the double track.

Some important points are found from analyzing the results as discussed in the following subsections.

\section{A. Deadlock}

When the traditional management of the movement of the supply trains is used, it is necessary to have a train on every double track point from the commencement of the muck evacuation process. Otherwise, the operation will experience deadlock, which means the operation cannot proceed and therefore stops. The deadlock occurs from the absence of a train waiting at a double track point. For example, when there is no incoming train at a double track point, no outgoing train is allowed to pass the double track, resulting in deadlock. Cases 4, 10, 13, 16 and 19 in Table III are those where there is no deadlock. In these cases, the number of supply trains equals the number of double tracks plus two, which means there is a train stopped at every double track from the commencement of the muck evacuation process plus a train at the shaft and another train at the TBM.

\section{B. Maximum Productivity Rate}

The productivity of this operation is measured in terms of the number of tunnel lining rings installed per day. One day equals 24 hours of construction. The maximum productivity predicted by the simulation is 27.8 rings per day. No breakdown of any equipment is included in the simulation model presented in this paper. This figure therefore represents the case where the operation runs smoothly. This predicted maximum productivity rate agrees with the average maximum productivity per day statistically recorded from previous projects by the tunnel-boring firm. 
Proc. of the Sixth Intl. Conf. Advances in Civil, Structural and Mechanical Engineering - CSM 2018 Copyright (C) Institute of Research Engineers and Doctors, USA. All rights reserved.

ISBN: 978-1-63248-150-4 doi: 10.15224/978-1-63248-150-4-23

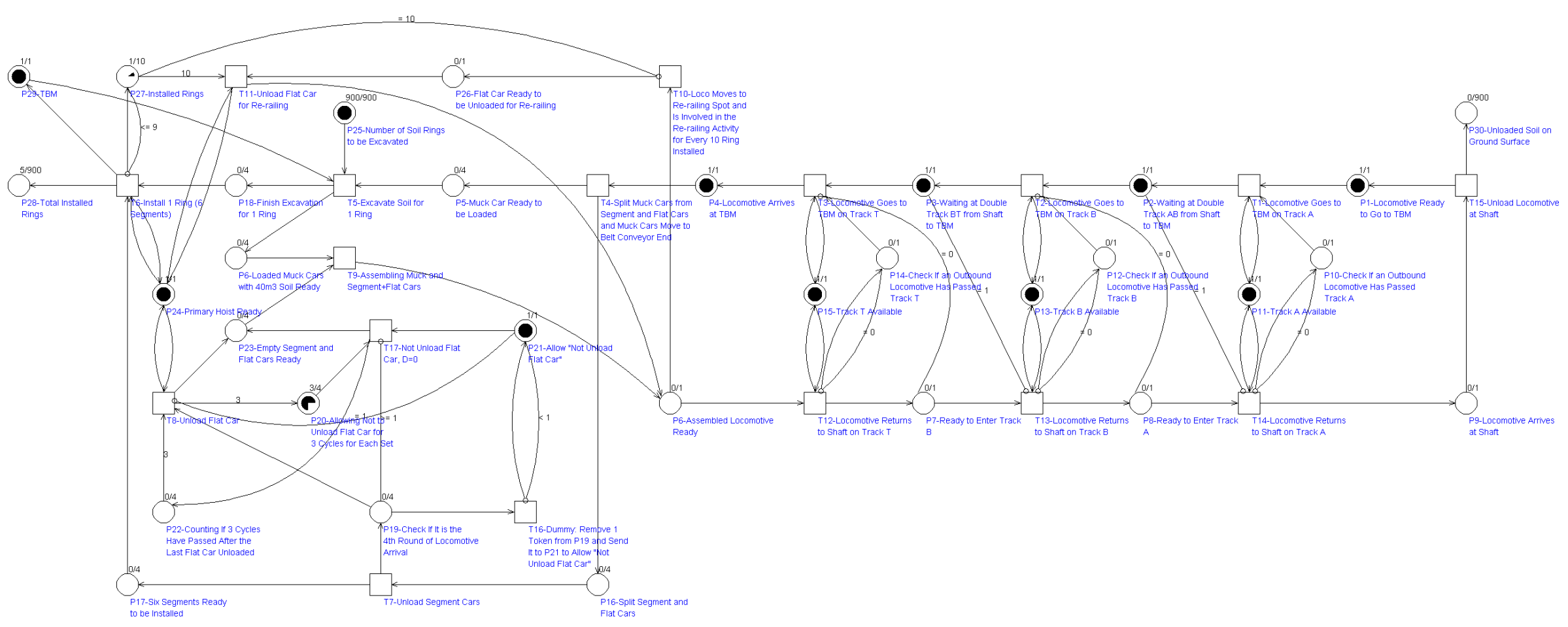

Figure 2. COSMOS model of the operation. 


\section{Maximum Permissible Length of Track T}

Track $\mathrm{T}$ is the portion of the railway for the supply trains located between the last double track point and the TBM. The length of track $\mathrm{T}$ is measured from the outgoing Y-point of the last double track to the furthest position of the front part of the back-up system which the supply trains can access. The furthest position is the location where the train will stop when it reaches the TBM. A Y-point is the point where a single and a double track are connected at a double track point.

To determine the maximum permissible length of track $\mathrm{T}$, another 3 cases were simulated, namely cases 20, 21 and 22 as shown in Table III. These cases differ by the tunnel lengths. The lengths for cases 20,21 and 22 are 0.9, 1.0 and $1.1 \mathrm{~km}$, respectively. No double track point and 2 supply trains are used in each case.

The simulation results indicate that the maximum permissible length of track $\mathrm{T}$ is $0.9 \mathrm{~km}$. The maximum length or any other shorter length allows the TBM to operate continuously with no idle time. This leads to the maximum productivity output. However, at the maximum permissible length, the supply train has to wait 1 minute on average for every TBM operational cycle. The train must wait after it has reached the TBM and has been split into 2 parts.

\section{Longest Permissible Distance from Tunnel Shaft to Nearest Double Track}

The longest permissible distance from the tunnel shaft to the Y-point of the first double track next to the shaft is 2.3 $\mathrm{km}$. If the distance is not longer than this, the maximum productivity rate of 27.8 rings per day can be expected. Otherwise, if the distance is longer than $2.3 \mathrm{~km}$, the productivity will decline relative to the increment of the distance beyond $2.3 \mathrm{~km}$.

It should be noted that the maximum distance of $2.3 \mathrm{~km}$ is still true for the maximum allowable distance between any two adjacent double track points.

\section{E. Optimal Numbers of Double Track Points and Supply Trains}

From the analysis in section $\mathrm{D}$, the numbers of the double tracks and the supply trains that will allow the operation to reach its maximum capacity of 27.8 rings per day can be given in Table IV. The results presented in this table are based on the condition that the number of the supply trains employed in the operation is minimal. Some double track points are needed to be closed when they are not necessary. The necessity is determined from the findings from sections $\mathrm{C}$ and $\mathrm{D}$ that the maximum permissible length of track $\mathrm{T}$ is $0.9 \mathrm{~km}$ and the maximum allowable distance between the nearest double track from the starting shaft and also between any two adjacent double track points are $2.3 \mathrm{~km}$.
TABLE IV. OPtimal Double TRack PoINTS ANd SupPly Trains

\begin{tabular}{|c|c|c|c|}
\hline $\begin{array}{c}\text { Max. Tunnel } \\
\text { Length } \\
(\mathbf{k m})^{\mathbf{a}}\end{array}$ & $\begin{array}{c}\text { Locations of } \\
\text { Opening } \\
\text { Double Track } \\
(\mathbf{k m})^{\mathbf{b}}\end{array}$ & $\begin{array}{c}\text { Locations of } \\
\text { Closed Double } \\
\text { Track } \\
(\mathbf{k m})^{\mathbf{b}}\end{array}$ & $\begin{array}{c}\text { Number of } \\
\text { Supply } \\
\text { Trains }\end{array}$ \\
\hline 0.9 & - & - & 2 \\
\hline 1.8 & 0.9 & - & 3 \\
\hline 2.7 & 1.8 & 0.9 & 3 \\
\hline 3.6 & $1.8,2.7$ & 0.9 & 4 \\
\hline 4.5 & $1.8,3.6$ & $0.9,2.7$ & 4 \\
\hline 5.4 & $1.8,3.6,4.5$ & $0.9,2.7$ & 5 \\
\hline \multicolumn{3}{|r}{} \\
\hline
\end{tabular}

a. Distance from the tunnel shaft to the front of the back-up system.

b. Distance from the tunnel shaft to the specific double track.

\section{vi. Conclusion}

The number of supply trains employed in the BeungNongbon drainage-tunnel project is optimized in such a way that the operation of the trains is well synchronized with that of the TBM. The optimization is achieved through the application of a modelling and simulation approach. A model representing muck evacuation, tunnel excavation and segment installation of the operation is developed using the COSMOS system. The optimization presented in this research can be applied to other projects involving tunnel boring and construction, which will provide necessary information for the efficient management of the operation.

\section{References}

[1] J. Damrianant, "COSMOS: a discrete-event methodology for construction processes," Int. J. Internet Enterprise Manag., vol. 1, pp. 128-152, April 2003.

[2] T. Murata, "Petri nets: Properties, analysis and application," Proc. IEEE, vol. 77, pp. 541-580, April 1989.

[3] Z. Chen and B. Shan, "The application of Petri Nets to construction project management," in Affective Computing and Intelligent Interaction, Advances in Intelligent and Soft Computing, vol. 137, J. Luo, Eds. Berlin: Springer, 2012, pp. 151-158.

[4] C. P. Lin and H. L. Dai, "Applying Petri Nets on project management,” Univers. J. Mech. Eng., vol. 2, pp. 249-255, 2014.

[5] TERRATEC Ltd., "TERRATEC tunnel boring machine - EPB series," unpublished.

About Author:

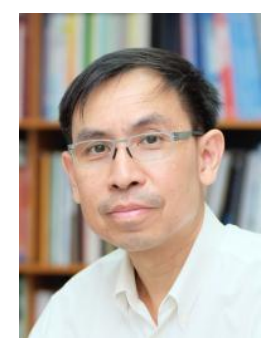

Jirawat Damrianant has a B.Eng. (Hons) in Civil Engineering from Chiang Mai University, a M.Eng. in Structural Engineering and Construction from Asian Institute of Technology, Thailand and a Ph.D. in Civil Engineering from the University of New South Wales, Australia. Dr. Damrianant has worked in the construction industry as a structural designer and a construction manager for several years. He is currently an assistant professor at Thammasat University, Thailand. His research interests include construction-process modeling and simulation, and other related topics in construction engineering and management. Dr. Damrianant is a registered professional civil engineer, a member of the Council of Engineers (Thailand) and a member of the Engineering Institute of Thailand under H.M. the king's patronage. He is also a specialist of the Council of Engineers. 